\title{
A Look at EFL Technical Students' Use of Learning Strategies in Taiwan
}

\author{
Yu-Wei Chu \\ Department of Applied English, HungKuang University \\ No. 34, Chung-Chie Road, Taichung City 43302, Taiwan R.O.C. \\ E-mail: yweichu@sunrise.hk.edu.tw \\ Bih-Shia Huang \\ Department of Applied English, HungKuang University \\ No. 34, Chung-Chie Road, Taichung City 43302, Taiwan R.O.C. \\ E-mail: bihshia@yahoo.com \\ Ming-Piao Shih \\ Department of Applied English, HungKuang University \\ No. 34, Chung-Chie Road, Taichung City 43302, Taiwan R.O.C. \\ E-mail: ming5157@gmail.com \\ Chih-Hsin Tsai (Corresponding author) \\ Department of Applied English, HungKuang University \\ No. 34, Chung-Chie Road, Taichung City 43302, Taiwan R.O.C. \\ E-mail:chtsai@sunrise.hk.edu.tw
}

Received: April 2, 2012

doi:10.5430/wje.v2n3p16
Accepted: May 3, 2012

Published: June 15, 2012

URL: http://dx.doi.org/10.5430/wje.v2n3p16

\begin{abstract}
253 freshmen taking Freshman English from a university of technology in the central Taiwan participated in this study. The purposes of this research were to explore what learning strategy was used more frequently by college students and to investigate the variance of using learning strategies among students of different English proficiency levels. The results indicated that the most frequently used strategy in learning English was Compensation and followed by Affective, Social, Memory, Metacognitive, and Cognitive strategies respectively. High proficiency students used these six learning strategies more frequently than low proficiency ones. All the six learning strategies existed positive correlation with English academic achievement individually.

It is suggested that teachers should explore a variety of different learning strategies with their students, and think carefully about which strategies offer the greatest prospect for improvement for students within a specific educational environment. Instructing learning strategies in class by EFL teachers will also promote students' motivation in learning English and enhance their learning effectiveness and efficiency.
\end{abstract}

Key words: Academic achievement, English proficiency, Learning strategy, University of Technology 


\section{Introduction}

For most Taiwanese students, English has been a pain in the neck. Despite of training for years, many students, especially students in technological and vocational systems, have more barriers than those in the general educational system. One major reason is that technological and vocational high school students receive fewer hours learning in English. More often than not English courses at these schools are replaced by other courses that are considered more 'practical'. These high school students almost forget the existence of English until they become freshmen at technological universities. In fact, English is a required course in the first year of universities. These former technological and vocational students are often frustrated when attending English courses.

Some people hold the belief that a proficient language learner must have good strategic plans. However, there was an interesting finding in which good L2 learners could replace a lack of English proficiency for alertness of strategic learning (Mokhtari \& Sheorey, 2002). This shows that learning strategies can compensate for insufficient language capability.

EFL students may improve English learning ability through the intervention program. In the intervention program, unskilled students such as EFL students, who suffer reading difficulty, should be encouraged by teachers to use the Metacognitive strategies. According to Ely and Lea Kozminsky's report (2001), "beginning readers require guidance in the use of strategies" (p. 188). Reading comprehension can be made by employing various strategies with the intervention program. Most often, students' awareness of strategies and ability to integrate them into their learning are not spontaneously generated on their own. In effect, they can be intentionally realized through instructional interventions (Alfassi, 2004). In the intervention program, teachers play a heuristic role in the program. Struggling students who become successful learners are closely tied to expert teachers (Fisher \& Ivey, 2006). The enforcement of linguistic and cognitive strategies in the intervention program for EFL students would improve students' reading comprehension (Schiff $\&$ Calif, 2004).

In Taiwan, regarding English learning strategies, some of the studies have been conducted. Liu, Wu, Zhou, Yang and Jiang (1989), Wu, Liu, Yang, and Zhou (1993), Goh and Kwah (1997), and Bremner (1999) conducted a large scale study on college students' learning strategies across China, Singapore, and Hong Kong. However, a cluster of learning strategies employed by students did little effect on language proficiency. The possible reasons could be that strategies used by students include several skill areas (speaking, listening, reading, and writing), and the different proficiency levels in each skill area might conceal the overall proficiency level of students investigated as Jiang (1994) and Zhang (2003) explained.

The purposes of this study were to investigate kinds of learning strategies used by freshmen from a university of technology in the central Taiwan, to compare various strategies used by learners of different English proficiency, and to identify the relationships between English academic achievement and learning strategies. This topic might be valuable if strategic learning patterns among good and poor EFL readers were proved distinguishable. Accordingly, EFL teachers may prescribe better strategies to those who need learning remedies.

\section{Literature Review}

Chinese learning context and learning culture are special from the westerns (Jin \& Gortazzi, 2002; Zhang, 2003). More research is required to understand the learning behavior of Chinese students to help them learn more effectively and efficiently.

\subsection{Definitions of Language Learning Strategies}

Strategies are particularly important for language learning as they are tools for active and self-directed involvement, which is essential for developing communicative competence (Oxford, 1990). Because of its significance, learning strategies are applied extensively in the filed of education. In defining the learning strategies, researchers use various terms in different concepts. A great number of researchers developed their own definitions of learning strategies which will be discussed as follows.

Rubin (1975) stated strategies as the techniques, which a learner may use to acquire knowledge. Later in 1987, Rubin pointed that learning strategies construct and affect learning directly as they contributed to the development of the language pattern. Rigney (1978) defined learning strategies as "cognitive strategy" which was "used to signify operations and procedures that the student may use to acquire, retain, and retrieve different kinds of knowledge and performance" (p.165). Bialystok (1979) reported that learning strategies as "operational means for exploiting available information to improve competence in a second language" (p.71).

Chamot (1987) gave a definition to learning strategies as "techniques, approaches or deliberate actions that students take in order to facilitate the learning and recall of both linguistic and content area information"(p.105). Nisbet \& Shucksmith 
(1986) offered another definition to learning strategies as "always purposeful and goal-oriented, but perhaps not always carried out at a conscious or deliberate level. They can be lengthy or so rapid in execution that it is impossible for the learner to recapture, recall or even be aware that one has used a strategy" (p.25).

Strategies are defined as learning techniques, behaviors, problem-solving or study skills which make learning more effective and efficient (Oxford and Crookall, 1989). They defined learning strategies as "steps taken by the learner to aid the acquisition, storage, and retrieval of information" (p.404). They reported that learners use learning strategies in conscious condition and might become habitual and automatic with practice. Oxford (1990) also claimed that "learning strategies are steps taken by students to enhance their own learning" (p.1). She proposed a more specific definition to learning strategies as "specific actions taken by the learner to make learning easier, faster, more enjoyable, more self-directed, more effective, and more transferable to new situation" (p.8).

Oxford (1990) offered a useful and comprehensive classification scheme of the various strategies used by learners and developed it into a questionnaire named the Strategy Inventory for Language Learning (SILL). He organized 50 items of the SILL into 6 strategy groups or factors, each containing varying numbers of items. The dimensions of SILL are listed as follows.

1. Cognitive strategies: The strategies are used by learners to transform the language material in a direct way, including note taking, summarizing, paraphrasing, predicting, reasoning, and analyzing (14 items).

2. Memory strategies: Techniques that help the learners to remember and retrieve information from various aspects, such as via sounds, images, a combination of sounds and images, body movement, or location. These include rhyming, grouping and associating, semantic mapping, using keyword methods, employing word associations and placing new words into a context (9 items).

3. Compensation strategies: These strategies include inferring and guessing skills from the context in listening and reading. Synonyms and reference materials (dictionaries) are generally adopted to apply in these strategies (6 items).

4. Metacognitive strategies: These strategies are identifying one's own learning style preferences and needs, which include behaviors undertaken by the learners to plan, arrange, and seek practice opportunities, gather and organize materials, monitor mistakes, evaluate task success, and evaluate the success of any type of learning strategy (9items).

5. Affective strategies: These strategies are identifying one's mood and anxiety level. Learners talk about their feelings, reward themselves for good performance, use deep breathing or positive self-talk and self-encouraging behavior to lower their anxiety, and promote their learning (6 items).

6. Social strategies: These strategies are those that help learners work with other individuals in the learning process and refer to cooperate with native speakers of the language, include questioning to get verification, asking for help in doing a language task, clarifying a confusing point, and giving feedback (6 items).

\subsection{Learning Strategies Used by College Students}

Yang (1993) adopted a modified version of Oxford's SILL to survey over five hundred college students. In six learning strategy categories, she found that these EFL students using the Compensation strategies, Affective strategies, and Metacognitive strategies more often. Bremner (1999) conducted a study and found that Compensation and Metacognitive strategies were the most used whereas Affective and Memory strategies were the leased use with a group of college students in Hong Kong. Chang, Liu, and Lee (2007) revealed that Compensation strategies was the most frequently used strategy, and followed by Memory strategies, Metacognitive strategies, Social strategies, Cognitive strategies, and Affective strategies by Taiwan college students.

Some studies have investigated the learning strategies used by successful (good) and unsuccessful (poor) language learners. Hosenfeld (1977) claimed that successful (good) learners kept the meaning of the passage in mind while learning. They read in broad phrases, skipped inconsequential or less important words, and had a positive self-concept as readers. The unsuccessful (poor) learners lost the meanings of the sentences when decoded, read in short phrases, thought over inconsequential words, seldom skipped words as unimportant, and had a negative self-concept. In Block's (1986) study, she found the group she designed as "integrator", were generally aware of text structure, responded in an extensive mode to the message conveyed by the author, and monitored their understanding consistently. The "non-integrators", on the other hand, failed to integrate, did not recognize text structure, and relied much more on personal experience. Overall, the "non-integrators" made less progress in developing their learning skills and demonstrated less success after one semester in college. 
Nunan (1991) stated that more effective learners differed from less effective learners in their greater ability to reflect on their own language learning processes. According to Green and Oxford (1995), in a study of learners of English in Puerto Rico, more successful students used strategies for active involvement more frequently than did less successful learners. Less proficient learners used strategies in a random, unconnected, and uncontrolled manner, while more effective learners showed careful use of strategies, targeted in a relevant, systematic way at specific second language tasks (Abraham \& Vann, 1989; Chamot, Barnhardt, El-Dinary, \& Robbins, 1996). They also discovered that second language learners generally employed more strategies (with a higher frequency) than did foreign language learners. Goh and Kwah (1997) did a survey with the students from the People's Republic of China (PRC) learning English as a second language in Singapore, aiming to found out how students' proficiency level influence their use of strategies.

Takeuchi (2003) also identified that a good language learner as one who was a mentally active learner, monitored language comprehension and production, practiced communicating in the language, made use of prior linguistic and general knowledge, used various memorization techniques, and asked questions for clarification. Chamot (2005) indicated that the strategy instruction affected the frequency of learners' use of the strategies only for the high proficiency level group. It would be that the low proficiency group probably needed was a focus on bottom-up processing strategies.

The distinction between good and poor readers lies only in whether they are able to use strategies in learning. Good learners differentiated from poor ones are more flexible when they are reading. Yang (2006) defined that good learners skipped unimportant words and had a positive self-concept as readers while poor readers read word by word and had a negative self-concept as readers. Lau (2003) pointed out that poor learners were deficient in reading processes including decoding, cognitive, and metacognitive strategies. Alfassi (2004) stated that an active learner constructs meaning through the integration of existing and new knowledge, and the flexible use of strategies to foster, monitor, regulate, and maintain comprehension. Good learners are active and metacognitive and have control over their learning (Zygouris-Coe, Wiggins, \& Smith, 2005).

Myers \& Paris (1978) demonstrated that poor learners did not engage in accurate monitoring as frequently as good learners. Furthermore, poor learners also demonstrated less accurate comprehension and recall of the stories than good learners. It was also found that good learners used Comprehension strategies far more frequently than poor learners. Most good learners reported using strategies of asking questions or referring to the dictionary to determine word meanings, while none of the poor learners did so. Olah (2006) reported that the use of Social strategies in university students correlated with a high level of English proficiency. Overall, poor learners engaged in a few spontaneous study behaviors, failed to ask questions, take notes or use a dictionary as often as good learners. High proficient learners, on the other hand, used cognitive, memory, metacognitive, compensation and social strategies to a far greater extent than low proficient learners.

Liu (1996) investigated the learners' learning strategy use and its relationship to the academic achievement. The results supported the relationship between learning strategies and learning outcomes. Chung (1999) also indicated positive relationship between the use of learning strategies and the achievement. However, there was a moderate correlation between social strategies and academic performance $(\mathrm{p}<.05)$ for university students in Japan (Olah, 2006).

\section{Method}

\subsection{Participants}

The participants of this study were 253 students from 6 Freshman English classes in a university of technology in central Taiwan. There were 60 males and 193 females. Stratified sampling was employed to select 298 students to take the questionnaire originally; however, only 253 students returned and provided useful data. Forty-six questionnaires were ruled out because of the incomplete responses.

The proficiency levels were defined based on students' English Placement Test Score, which allocated students into different classes fairly by S distribution. 64 students whose English Placement Test Scores were located at the range of first $25 \%$ from 253 students were defined as high proficiency students. 66 students whose scores were located at the range of last $25 \%$ from 253 students would be defined as low proficiency students.

\subsection{Instruments}

Two instruments adopted in this study were described as follows.

\section{English Academic Achievement Test}

It was a Freshman English final exam administered to all the freshmen by the end of spring semester, 2009. All the questions were developed by Live ABC Interactive Cooperation. 


\section{Chinese Strategy Inventory for Language Learning (Chinese SILL)}

Strategy Inventory for Language Learning SILL, EFL/ESL 7.0 version (Oxford, 1990) was adapted in this study. The SILL is recognized as the best way to discover the learning strategies of EFL/ESL students, because it is a questionnaire based on self-assessment, in which the students can reflect upon, and give honest answers about the ways in which they learn. Chinese version of SILL was translated by Yang in 1992. It contains 49 items, and is characterized into six subscales: Memory strategies (items 1 to 9), Cognitive strategies (items 10 to 23), Compensation strategies (item 24 to 29), Metacognitive strategies (items 30 to 38), Affective strategies (items 39 to 43), and Social strategies (items 44 to 49 ). These SILL 49 items were evaluated on a five-point Likert scale ranging from 1 to 5: never or almost never true of me, generally not true of me, somewhat true of me, generally true of me, and always or almost always true of me, somewhat true of me, generally true of me, and always or almost always true of me. This Chinese SILL was administered to 590 students from Taiwan University by Yang (1992) and it provided high internal consistency reliability $(\alpha)$ to .94. In this study, the overall Cronbach's alpha equaled .96, which was consistently high as the Chinese SILL examined by Yang (1992).

\subsection{Procedures}

Two hundred and fifty-three students from 6 Freshman English classes, which were instructed by three lecturers, were selected as participants at the beginning of fall semester. By the end of the spring semester next year, Freshman English final exam was carried out as English Academic Achievement Test. Chinese SILL (Yang, 1992) was administered along with the final exam at the same time. All participants were informed of their rights of confidentiality before responding to the questionnaires. The teachers encouraged the students to answer every question carefully and informed them that all of the responses would be kept anonymous. There was no time limit in answering these questions.

\subsection{Data Analysis}

SPSS 12.00 statistical package was used to compute collected data. Mean value and standard deviation were analyzed by descriptive statistics to examine each subscales of SILL. One one-way analysis of variance (ANOVA) method was used to reveal the main effect of six strategies categories based on the different proficiency levels of the students. One correlation was adopted to evaluate the relationship among English academic achievement and six subscales in Chinese SILL. The probability level of significance for t-test and ANOVA was set at .05.

\section{Results}

In this study, internal consistency reliability of this questionnaire (SILL) administered to 253 first-year college students was analyzed. The overall Cronbach alpha reliability was. 96, and was higher than the Chinese version of SILL (.94) (Yang, 1992). It showed that this questionnaire had a good internal consistency to evaluate student's learning strategy use.

\section{Question 1: What kinds of learning strategies do students in a university of technology report using?}

Descriptive statistics was computed to understand what strategies were used more often by learners in a university of technology. Mean values and standard deviation of various categories in learning strategies were listed in Table 1. Apart from showing the frequency of use of each learning strategy most and least frequently used, the data also indicated that the students in general did not apply learning strategies very often. The mean value of overall strategies was 2.91 , which was approximately at a medium degree (with a range from 1 to 5). The most used strategy of learning strategy was Compensation $(M=3.06)$, and followed by Affective $(M=2.95)$, Social $(M=2.95)$, Memory $(M=2.92)$, Metacognitive $(\mathrm{M}=2.87)$, and Cognitive $(\mathrm{M}=2.73)$ respectively.

Actually, a slight difference existed among students in using those learning strategies.

<Table 1 about here>

\section{Question 2: Does language proficiency influence students' use of learning strategies?}

One-way ANOVA was performed to examine the relationship between proficiency level and frequency of strategy use this study. Regarding the students with different proficiency levels in English, Table 2 indicated that significant differences existed with respect to Memory strategies $(\mathrm{F}=6.92, \mathrm{p}<.01)$, Cognitive strategies $(\mathrm{F}=13.61$, $\mathrm{p}<.001)$, Compensation strategies $(\mathrm{F}=18.12, \mathrm{p}<.001)$, Metacognitive strategies $(\mathrm{F}=16.23 . \mathrm{p}<.001)$, Affective strategies $(\mathrm{F}=8.55, \mathrm{p}<.01)$ and social strategies $(\mathrm{F}=9.25, \mathrm{p}<.01)$. The mean scores revealed that high proficiency students were the high frequency users of these six learning strategies than those in low proficiency.

$<$ Table 2 about here> 


\section{Question 3: Is there a correlation between learning strategies use and English Academic Achievement Test?}

Correlation was adapted to investigate the relationship between learning strategies use and English Academic Achievement Test. The result in Table 3 revealed all the six learning strategies were correlated with English Achievement Test individually. Memory, Cognitive, Compensation, Metacognitive and Social strategies presented significant positive correlation with English Academic Achievement Test $(\mathrm{p}<.05)$, respectively. There was only a moderate correlation between English Academic Achievement Test and Affective strategies $(\mathrm{p}<.05)$.

$<$ Table 3 about here>

\section{Discussion}

The results of this study shed light on the types of learning strategies used by students in a university of technology, and more important, how these strategies affected students' English academic achievement based on proficiency differences.

Oxford (1990) defined that strategies with a mean value higher than 3.5 are regarded as of frequently use, medium use was as the mean between 2.5 and 3.4. In this study, the mean value of the frequency of overall strategy use was 2.91, which was only in a slight higher half of mean use for all the 49 strategies. As a result, all of the six strategies were labeled between in the range from 2.73 to 3.06 , which certainly indicated a medium use in this study. This result was consistent with the research that learners didn't apply learning strategies as frequently as they would when they were learning a second language in the technical university (Chang, Liu, \& Lee, 2007).

In addition, the category of learning strategy used most frequently by learners in this study was Compensation strategies. The result was consistent with some previous research, which indicated that university students used Compensation most often in learning English in Taiwan (Chang, Liu, \& Lee, 2007; Ksu, 1995; Yang, 1992). Similar to Chang's et. al. (2007), Hsu's (2007) and Jiang \& Liao's (2006) studies, Cognitive strategies were the used least frequently by all the students. Cognitive strategies, including skimming, scanning, predicting, inferring and summarizing etc., which were taught in class to facilitate students' English learning proficiency, most of the students didn't concentrate mostly on those strategies learning as they were familiar with them since elementary school. Rigney (1978) stated that Cognitive strategies had been strengthened by teachers in students' early school life. It could be a reason to explain why Cognitive strategies were the least frequently used factor among the six strategies in this study, which could implicate that students neglected these strategies in learning English.

In this study, significant differences existed among different proficiency levels with respect to all the strategies in Chinese SILL: Memory, Cognitive, Compensation, Metacognitive, Affective and Social strategies. The mean scores revealed that high proficiency students were the more frequent users of these six learning strategies than those of low proficiency. This result was consistent with previous studies, which showed that high proficiency students tended to use a wider range of strategies and used strategies more frequently than low proficiency students (Alfassi, 2004; Anderson, 1991; Chang et al, 2007; Deegan, 1995; Jiang, 1994; Lau 2003; Meyers, 1981; \& Zhang , 2003). Especially in using Cognitive, Compensation and Metacognitive strategies by students, they reached a significant difference at .01 level.

There was a high correlation between learning strategies and student's English academic achievement. As was pointed out in the results section, five strategies (Memory, Cognitive, Compensation, Metacognitive, and Social) proved to have strong correlation with English Academic Achievement Test, which showed a moderate correlation with Affective. These findings were consistent with Liu's (1996) and Chung's (1999) studies. Students with high English academic performances seemed to be applying the learning strategies more frequently, effectively and appropriately than those with low English academic performances. It's also interesting to reveal that although Affective strategies only provided a moderate correlation with English academic achievement, it was the second most frequently used strategy in this study as listed previously as well.

To conclude, students used indirect learning strategies (e.g. Compensation and Affective strategies) more frequently than the direct learning ones (e.g. Cognitive strategies). Using learning strategies well is essentially beneficial to students in learning the second language. It is important for cultivating and raising student's awareness of learning strategies, which may facilitate their learning in English.

\section{Implications}

The findings of this study revealed that students from the technical university preferred using Compensation, Affective, Social and Memory more to Cognitive and Metacognitive strategies, which may indicate that traditional teacher-centered pedagogical practices seem not to be feasible for students in this school system. More creative and practical pedagogy is exigent and imperative to be expanded for EFL learners. Student-centered pedagogy like cooperative learning may establish an interactive and motivated phenomenon to facilitate students in learning English. In cooperative learning, 
students work together in small, heterogeneous groups to complete a problem, project, or other instructional goal, while teachers act as guides or facilitators. This method works to reinforce a student's own learning as well as the learning of his or her fellow group members. It seems as a feasible approach for those college students from technical educational system, who are used to using Compensation, Affective and Social strategies more frequently in learning English.

This study gave strong support to studies that have proved a relationship between learning strategies and English academic achievement. Most of the students are not always aware the power of consciously using learning strategies. Skilled teachers should help their students to develop an awareness of learning strategies and enable them to use a wide range of appropriate strategies. Making a positive link between learning proficiency and teaching process could enhance students' learning autonomy and independence.

It is suggested that in addition to encouraging students to be more diligent, teachers should teach a variety of learning strategies to their students, and think carefully about which strategies offer the greatest prospect of improvement for students within a specific educational environment. Helping students to be aware of the importance of learning strategies use and teaching them how to use learning strategies well could help them learn more effectively.

\section{References}

Abraham, R., \& Vann, R., (1989). Strategies of two learners: A case study. In A.L. Wenden \& J. Rubin (Eds.), Learner Strategies in Language Learning (pp.85-102). New York: Prentice Hall.

Alfassi, M. (2004). Reading to Learn: Effects of Combined Strategy Instruction on High School Students. The Journal of Educational Research, 97 (4), 171-184. http://dx.doi.org/10.3200/JOER.97.4.171-185

Anderson, N. (1991). Individual differences in strategy use in second language reading and testing. Modern Language Journal, 75, 460-472. http://dx.doi.org/10.1111/j.1540-4781.1991.tb05384.x

Bialystok, E. (1979). The role of conscious strategies in second language proficiency. Canadian Modern Language Review, 35, 372-394. http://dx.doi.org/10.2307/3586295

Block, E. (1986). The comprehension strategies of second language readers. TESOL Quarterly, 20(3), 463-494. http://dx.doi.org/10.2307/3586295

Bremner, S. (1999). Language learning strategies and language proficiency: Investigating the relationship in Hong Kong. Canadian Modern Language Review, 55(4).

Chang, C. Y., Liu, S. C., \& Lee, Y. N. (2007). A study of language strategies used by college EFL learners in Taiwan. MingDao General Education Journal (2), 235-262. http://dx.doi.org/10.3138/cmlr.55.4.490

Chamot, A. U. (1987). The learning strategies of ESL students. In A. Wenden \& Wenden \& J. Rubin (Eds.), Learner strategies in language learning (pp. 71-83). Englewood Cliffs, NJ: Prentice-Hall.

Chamot, A. U. (2005). Language learning strategy instruction: Current issues and research. Annual Review of Applied Linguistics, 25, 112-130. http://dx.doi.org/10.1017/S0267190505000061

Chamot, A. U., Barnhardt, S., El-Dinary, P., \& Robbins, J., (1996). Methods for teaching learning strategies in the foreign language classroom. In R. Oxford (Ed.), Language Learning Strategies Around the World: Cross-cultural Perspectives (pp.175-188). Manoa: University of Hawaii Press.

Chung, C. F. (1999). An investigation of FHK cadets' use of English learning strategies and their relationship to learning achievement. Master's thesis, Fu Hsing Kang College.

Fisher, D., \& Ivey, G.. (2006). Evaluating the Interventions for Struggling Adolescent Readers. Journal of Adolescent \& Adult Literacy, 50 (3),

Friend, R. (2001). Teaching Summarization as a Content Area Reading Strategy. Journal of Adolescent \& Adult Literacy, 44 (4), 320-329.

Goh, C., \& Kwah, P. F. (1997). Chinese ESL students' learning strategies: A look at frequency, proficiency and gender. Hong Kong Journal of Applied Linguistics, 2, 39 - 53.

Green, J. M., \& Oxford, R. (1995). A closer look at learning strategies, L2 proficiency, and gender. TESOL Quarterly, 29(2), 261-297. http://dx.doi.org/10.2307/3587625

Hosenfeld, C. (1977). A preliminary investigation of the reading strategies of successful and nonsuccessful second language learners. System 5, 110-123. http://dx.doi.org/10.1016/0346-251X(77)90087-2 
Hsu, S. C. (2007). Reading Strategies Used by EFL Technical Students. English Teaching e-Monthly, 22.

Jiang, Z. (1994). The Relationship Between Listening Strategies and Listening Comprehension. Foreign Language Teaching and Research, 26 (1), 51-58.

Jiang, M. \& Lian, B. (2006)。To explore Technical Students' Use of Learning Strategies between English Majored and Non English Majored students. English Educational Electronic Journal, 22.

Jin, L., \& Cortazzi, M. (2002). English language teaching in China: A bridge to the future. In W. K. Ho \& R. Wong (Eds.), English language teaching in East Asia today: Changing policies and practices. Singapore: Times Academic Press.

Kozminsky, E. , \& Kozminsky L. How Do General Knowledge and Reading Strategies Abilities Relate to Reading Comprehension of High School Students at Different Educational Levels? Journal of Research in Reading, 24 (2), 187-204. http://dx.doi.org/10.1111/1467-9817.00141

Lau, K. (2003). Reading Strategy Use and Motivation among Chinese Good and Poor Readers in Hong Kong. Journal of Research in Reading, 26 (2), 177-190. http://dx.doi.org/10.1111/1467-9817.00195

Liu, D. M. (1996). The relationship between language learning strategies used by high school EFL students in the Republic of China and their English achievement. Unpublished doctoral dissertation. State University of New York at Albany.

Liu, R., Wu, Y., Zhou, Y., Jeffery, P., Yang, y., \& Jiang, Z. (1989). A Survey Report of Tertiary English Education. Foreign Language Teaching and Research, 21 (3), 3-7.

Mokhtari, K., \& Sheorey, R. (2002). Measuring ESL Students' Awareness of Reading Strategies. Journal of Developmental Education, 25 (3), 1-10.

Myers, M., \& Paris, S. (1978). Children's metacognitive knowledge about reading. Journal of Educational Psychology, 70, 680-690. http://dx.doi.org/10.1037/0022-0663.70.5.680

Nisbet, J., \& Shucksmiath, J. (1986). Learning Strategies. NY: Routledge.

Nunan, D. (1991). Language teaching methodology. London: Prentice Hall.

Olah, B. (2006). ESL learning strategies, motivation, and proficiency: A comparative study of university and high school students in Japan. 文京學院大學人間學部研究紀要, 8(1), 189-205.

Oxford, R. L. (1990). Language learning strategies: What every teacher should know. New York: Newbury House Publishers.

Oxford, R., L.\& Crookall, D. (1989). Research on language learning strategies: Methods, findings, and instructional issues. Modern Language Journal, 73, 404-419. http://dx.doi.org/10.1111/j.1540-4781.1989.tb05321.x

Rigney, J. W. (1978). Learning strategies: A theoretical perspective. In H. F. O’Neil, Jr. (Ed.), Learning Strategies (pp.165-205). NY: Academic.

Rubin, J. (1975). What the "good language learner" can teach us. TESOL Quarterly, 9, 41-51. http://dx.doi.org/10.2307/3586011

Takeuchi, O. (2003). What can we learn from good language learners: A qualitative study in the Japanese foreign language context. System, 31, 385-392. http://dx.doi.org/10.1016/S0346-251X(03)00049-6

Yang, N. D. (1992). Second language learners' beliefs about language learning and their use of language learning strategies: A study of college students of English in Taiwan. Unpublished doctoral dissertation, University of Texas at Austin, Texas.

Yang, N. D. (1993). Beliefs about language learning and learning strategy use: A study of college students of English in Taiwan. The tenth conference on English teaching and learning in R. O. C. (pp.193-219). Taipei: The Crane Publishing Co.

Yang, Y. (2006). Reading Strategies or Comprehension Monitoring Strategies? Reading Psychology, 27, $313-343$. http://dx.doi.org/10.1080/02702710600846852

Wu, Y., Liu, R., Jeffery, P., Yang, Y., \& Zhou, Y. (1993). A Survey on Student Qualities of English Majors in Chinese Universities. Foreign Language Teaching and Research, 25 (1), 36-44.

Zhang, L. J. (2003). Research into Chinese EFL Learner Strategies: Methods, Findings and Instructional Issues. RELC, 34 (3), 284-322. http://dx.doi.org/10.1177/003368820303400303

Zygouris-Coe, V., Wiggins, M. B., \& Smith, L. (2005). Engaging students with text-3-2-1 Strategy. The Reading Teacher, 58 (4), 381-384. http://dx.doi.org/10.1598/RT.58.4.8 
Table 1. Summary of Descriptive Statistics for Learning Strategy Use

\begin{tabular}{|l|c|c|ll|}
\hline Strategy Category & $\begin{array}{c}\text { Numbers } \\
\text { Of Items }\end{array}$ & M & SD \\
\hline Memory & 9 & 2.92 & 0.61 & \\
\hline Cognitive & 14 & 2.73 & 0.59 & \\
\hline Compensation & 6 & 3.06 & 0.63 & \\
\hline Metacognitive & 9 & 2.87 & 0.64 & \\
\hline Affective & 5 & 2.95 & 0.72 & \\
\hline Social & 6 & 2.95 & 0.69 & $\mathrm{n}=253$ \\
\hline Overall & & 2.91 & & \\
\hline
\end{tabular}

Table 2. One-way ANOVA in Learning Strategy from Students in Different Proficiency Levels

\begin{tabular}{llllll}
\hline & \multicolumn{2}{c}{ High Proficiency } & \multicolumn{2}{c}{ Low Proficiency } \\
& \multicolumn{2}{c}{$\mathrm{n}=64$} & \multicolumn{2}{c}{$\mathrm{n}=66$} \\
Category & $\mathrm{M}$ & $\mathrm{SD}$ & $\mathrm{M}$ & $\mathrm{SD}$ & $\mathrm{F}$ \\
\hline Memory & 3.06 & .58 & 2.79 & .58 & $6.92^{* *}$ \\
Cognitive & 2.94 & .53 & 2.58 & .56 & $13.61^{* * *}$ \\
Compensation & 3.30 & .60 & 2.86 & .60 & $18.12^{* * *}$ \\
Metacognitive & 3.14 & .66 & 2.70 & .57 & $16.23^{* * *}$ \\
Affective & 3.20 & .69 & 2.85 & .66 & $8.55^{* *}$ \\
Social & 3.16 & .72 & 2.81 & .59 & $9.25^{* *}$ \\
\hline \multicolumn{1}{c}{$* * \mathrm{p}<.01$} & $* * * \mathrm{p}<.001$ & & & &
\end{tabular}

Table 3. Correlation Analysis between English Academic Achievement Test and Learning Strategy Use

\begin{tabular}{|c|c|c|c|c|c|c|}
\hline & Memory & Cognitive & Compensation & Metacognitive & Affective & Social \\
\hline Test & $.285^{* *}$ & $.225 * *$ & $.207 * *$ & $.230^{* *}$ & $.151^{*}$ & $.170^{* *}$ \\
\hline
\end{tabular}

